Pacific Journal of Mathematic

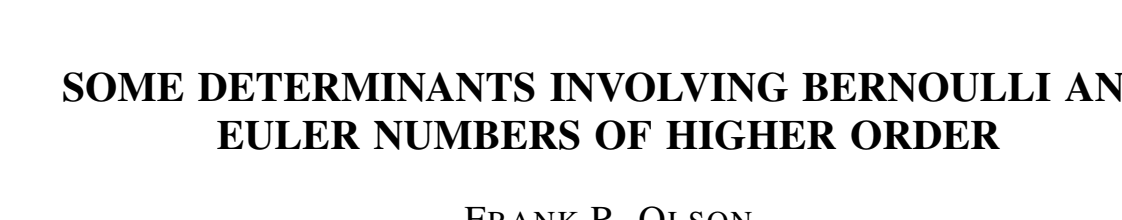




\title{
SOME DETERMINANTS INVOLVING BERNOULLI AND EULER NUMBERS OF HIGHER ORDER
}

\author{
Frank R. OLSON
}

1. Introduction. In this paper we evaluate certain determinants whose elements are the Bernoulli, Euler, and related numbers of higher order. In the notation of Nörlund [1, Chapter 6] these numbers may be defined as follows: the Bernoulli numbers of order $n$ by

$$
\left(\frac{t}{e^{t}-1}\right)^{n}=\sum_{v=0}^{\infty} \frac{t^{v}}{v !} B_{v}^{(n)}
$$

the related " $D$ " numbers by

$$
\left(\frac{t}{\sin t}\right)^{n} \sum_{v=0}^{\infty}(-1)^{v} \frac{t^{2 v}}{(2 v) !} L_{2 v}^{(n)} \quad\left(D_{2 v+1}^{(n)}=0\right)
$$

the Euler numbers of order $n$ by

$$
(\sec t)^{n}=\sum_{v=0}^{\infty}(-1)^{v} \frac{t^{2 v}}{(2 v) !} E_{2 v}^{(n)} \quad\left(E_{2 v+1}^{(n)}=0\right)
$$

and the " $C$ "' numbers by

$$
\left(\frac{2}{e^{t}+1}\right)^{n}=\sum_{v=0}^{\infty} \frac{t^{v}}{v !} \frac{C_{v}^{(n)}}{2^{v}}
$$

(By $n$ we denote an arbitrary complex number. When $n=1$, we omit the upper index in writing the numbers; for example, $B_{v}^{(1)}=B_{v}{ }^{\circ}$ )

We evaluate determinants such as

$$
\left|B_{i}^{\left(x_{j}\right)}\right|
$$$$
(i, j=0,1, \cdots, m)
$$

for the Bernoulli numbers, and similar determinants for the other numbers. The Received July 29, 1953.

Pacific J. Math. 5 (1955), 259-268 
proofs of these results follow from the evaluation of a determinant of a more general nature; see (3.4), below. Finally, a number of applications are given.

2. Preliminaries and notation. The numbers $B_{v}^{(n)}, D_{2 v}^{(n)}, E_{2 v}^{(n)}$, and $C_{v}^{(n)}$ may be expressed as polynomials in $n$ of degree $v[1$, Chapter 6$]$; in particular,

$$
B_{0}^{(n)}=D_{0}^{(n)}=E_{0}^{(n)}=C_{0}^{(n)}=1
$$

Although little is known about these polynomials, it will suffice for our purposes to give explicitly the values of the coefficients of $n^{v}$ in each of the four cases.

Considering first the Bernoulli numbers, we use the recursion formula [1, p. 146]

$$
B_{v}^{(n)}=-\frac{n}{v} \sum_{s=1}^{v}(-1)^{s}\left(\begin{array}{l}
v \\
s
\end{array}\right) B_{s} B_{v-s}^{(n)} .
$$

I et

$$
\begin{aligned}
& B_{v}^{(n)}=b_{v} n^{v}+b_{v-1} n^{v-1}+\cdots+b_{0}, \\
& B_{v-1}^{(n)}=b_{v-1}^{\prime} n^{v-1}+b_{v-2}^{\prime} n^{v-2}+\cdots+b_{0}^{\prime},
\end{aligned}
$$

and compare coefficients of $n^{v}$ on both sides of (2.1). We find that

$$
b_{v}=-\frac{1}{v}(-1)\left(\begin{array}{l}
v \\
1
\end{array}\right) B_{1} b_{v-1}^{\prime} .
$$

But $B_{1}=-1 / 2$ and therefore $b_{v}=-b_{v-1}^{\prime} / 2$. Since $B_{0}^{(n)}=1$, the preceding leads us recursively to

$$
B_{v}^{(n)}=\left(-\frac{1}{2}\right)^{v} n^{v}+b_{v-1} n^{v-1}+\cdots+b_{0}
$$

In a similar fashion the formula [1, p. 146]

$$
C_{v+1}^{(n)}=-n \sum_{s=0}^{v}(-1)^{s}\left(\begin{array}{l}
v \\
s
\end{array}\right) C_{s} C_{v-s}^{(n)},
$$

coupled with $C_{0}^{(n)}=1$, permits us to write 


$$
C_{v}^{(n)}=(-1)^{v} n^{v}+c_{v-1} n^{v-1}+\cdots+c_{0}
$$

As for the Euler numbers, we consider the symbolic formula $[1, p .124]$

$$
\left(E^{(n)}+1\right)^{2 v}+\left(E^{(n)}-1\right)^{2 v}=2 E_{2 v}^{(n-1)}
$$

in which, after expansion, exponents on the left side are degraded to subscripts. Hence we have

$$
E_{2 v}^{(n)}+\frac{(2 v)(2 v-1)}{1 \cdot 2} E_{2 v-2}^{(n)}+\cdots=E_{2 v}^{(n-1)}
$$

Writing

$$
E_{2 v}^{(n)}=e_{v} n^{v}+e_{v-1} n^{v-1}+\cdots+e_{0}
$$

and

$$
E_{2 v-2}^{(n)}=e_{v-1}^{\prime} n^{v-1}+e_{v-2 n}^{\prime} n^{v-2}+\cdots+e_{0}^{\prime}
$$

we see first that

$$
E_{2 v}^{(n)}-E_{2 v}^{(n-1)}=v e_{v} n^{v-1}+\text { terms of lower degree. }
$$

Hence comparing coefficients of $n^{v-1}$ in $(2.6)$ we have

$$
e_{v}=-\frac{(2 v)(2 v-1)}{2 v} e_{v-1}^{\prime}
$$

Since $E_{0}^{(n)}=1$, we obtain recursively

$$
E_{2 v}^{(n)}=\frac{(2 v) !}{(-2)^{v} v !} n^{v}+e_{v-1} n^{v-1}+\cdots+e_{0} .
$$

Next, from [1, p. 129]

$$
\left(D^{(n)}+1\right)^{2 v+1}-\left(D^{(n)}-1\right)^{2 v+1}=2(2 v+1) D_{2 v}^{(n-1)},
$$

we find that 


$$
D_{2 v}^{(n)}=\left(-\frac{1}{6}\right)^{v} \frac{(2 v) !}{v !} n^{v}+d_{n-1} n^{v-1}+\cdots+d_{0}
$$

We shall employ the difference operator $\Delta_{d}=\Delta$ for which

$$
\Delta f(x)=f(x+d)-f(x) \text { and } \Delta^{v}=\Delta \cdot \Delta^{v-1} \text {. }
$$

We recall that if

$$
f(x)=a_{v} x^{v}+a_{v-1} x^{v-1}+\cdots+a_{0},
$$

then

$$
\Delta^{v} f(x)=a_{v} d^{v} v !
$$

3. Main results. Let

$$
f_{n}(x)=a_{n, n} x^{n}+a_{n, n-1} x^{n-1}+\cdots+a_{n, 0} \quad\left(a_{n, n} \neq 0\right),
$$

and consider the determinant

$$
\left|f_{i}\left(x_{j}\right)\right| \quad(i, j=0,1, \cdots, m)
$$

This may be written as the product of the two determinants

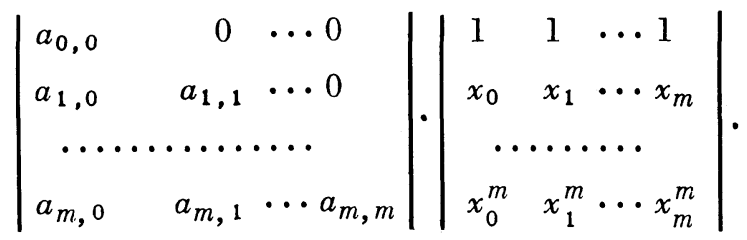

The first determinant in (3.3) reduces simply to the product of the elements on the main diagonal, and the second is the familiar Vandermond determinant. Hence

$$
\left|f_{i}\left(x_{j}\right)\right|=\prod_{k=0}^{m} a_{k, k} \prod_{r>s}\left(x_{r}-x_{s}\right) \quad(r, s=0,1, \cdots, m) .
$$

If we let

$$
f_{i}\left(x_{j}\right)=B_{i}^{\left(x_{j}\right)}
$$


then it follows from (3.4) and (2.2) that

$$
\left|B_{i}^{\left(x_{j}\right)}\right|=\prod_{k=0}^{m}\left(-\frac{1}{2}\right)^{k} \prod_{r>s}\left(x_{r}-x_{s}\right) \quad(i, j, r, s=0,1, \cdots, m) .
$$

Application of (3.4) to (2.4), (2.7), and (2.9) yields results of a similar nature for the $C, D$, and $E$ numbers. Consequently we have:

Theorem 1. For $i, j=0,1, \cdots, m$,

$$
\left|B_{i}^{\left(x_{j}\right)}\right|=\prod_{k=0}^{m}\left(-\frac{1}{2}\right)^{k} \prod_{r>s}\left(x_{r}-x_{s}\right)
$$

$$
\left|C_{i}^{\left(x_{j}\right)}\right|=\prod_{k=0}^{m}(-1)^{k} \prod_{r>s}\left(x_{r}-x_{s}\right)
$$

(iii )

$$
\left|D_{2 i}^{\left(x_{j}\right)}\right|=\prod_{k=0}^{m}\left(-\frac{1}{6}\right)^{k} \frac{(2 k) !}{k !} \prod_{r>s}\left(x_{r}-x_{s}\right)
$$

(iv)

$$
\left|E_{2 i}^{\left(x_{j}\right)}\right|=\prod_{k=0}^{m}\left(-\frac{1}{2}\right)^{k} \frac{(2 k) !}{k !} \prod_{r>s}\left(x_{r}-x_{s}\right)
$$

If we take $x_{j}=a+j d$ then we obtain:

Corolla Ry 1. For $i, j=0,1, \cdots, m, a$ and $d$ constants,

$$
\left|B_{i}^{(a+j d)}\right|=\prod_{k=0}^{m}\left(-\frac{d}{2}\right)^{k} k !
$$

$$
\left|C_{i}^{(a+j d)}\right|=\prod_{k=0}^{m}(-d)^{k} k !
$$

$$
\left|D_{2 i}^{(a+j d)}\right|=\prod_{k=0}^{m}\left(-\frac{d}{6}\right)^{k}(2 k) !,
$$

$$
\left|E_{2 i}^{(a+j d)}\right|=\prod_{k=0}^{m}\left(-\frac{d}{2}\right)^{k}(2 k) !
$$


If we let

$$
f_{i}\left(a+x d_{i}\right)=g_{i}(x)
$$

$f_{i}(x)$ defined as in (3.1), then we can readily show by the above method that

$$
\left|f_{i}\left(a+j d_{i}\right)\right|=\prod_{k=0}^{m} a_{k, k} d_{k}^{k} k ! \quad(i, j=0,1, \cdots, m)
$$

Hence (3.6) implies

$$
\left|B_{i}^{\left(a+j d_{i}\right)}\right|=\prod_{k=0}^{m}\left(-\frac{d_{k}}{2}\right)^{k} k !
$$

with like results for the other numbers.

We remark that the determinants of Corollary 1 may also be evaluated by a succession of column subtractions.

4. Applications. We consider first the determinant

$$
\left|B_{i}^{(a+j d)}(x)\right| \quad(i, j=0,1, \cdots, m ; a, d \text { constants }),
$$

where $B_{i}^{(n)}(x)$ is the Bernoulli polynomial of order $n$ defined by $[1, p .145]$

$$
\left(\frac{t}{e^{t}-1}\right)^{n} e^{x t}=\sum_{r=0}^{\infty} \frac{t^{v}}{v !} B_{v}^{(n)}(x) .
$$

(For $x=0, B_{v}^{(n)}(0)=B_{v}^{(n)}$, the Bernoulli number of order $n_{.}$) Also, by [1, p. 143 ],

$$
B_{v}^{(n)}(x)=\sum_{s=0}^{v}\left(\begin{array}{l}
v \\
s
\end{array}\right) x^{v-s} B_{s}^{(n)}
$$

Consequently

$$
\left|B_{i}^{(a+j d)}(x)\right|=\left|\sum_{s=0}^{i}\left(\begin{array}{l}
i \\
s
\end{array}\right) x^{i-s} B_{s}^{(a+j d)}\right| .
$$

If we define 


$$
\left(\begin{array}{l}
0 \\
0
\end{array}\right)=1 \text { and }\left(\begin{array}{l}
i \\
j
\end{array}\right)=0 \text { for } j>i
$$

then the right member of (4.2) may be written as the product of the two determinants;

$$
\left|\left(\begin{array}{l}
i \\
j
\end{array}\right) x^{i-j}\right| \cdot\left|B_{i}^{(a+j d)}\right|
$$

The first determinant has value 1 and hence, by Corollary 1(i),

$$
\left|B_{i}^{(a+j d)}(x)\right|=\prod_{k=0}^{m}\left(-\frac{d}{2}\right)^{k} k !
$$

The Bernoulli polynomials may also be expressed in terms of the $D$ numbers by $[1, p .130]$

$$
B_{v}^{(n)}(x)=\sum_{s=0}^{[v / 2]}\left(\begin{array}{c}
v \\
2 s
\end{array}\right)\left(x-\frac{n}{2}\right)^{v-2 s} D_{2 s}^{(n)} / 2^{2 s}
$$

If in (4.3) we let $x=h n, h \neq 1 / 2$, then

$$
B_{v}^{(n)}(h n)=\sum_{s=0}^{[v / 2]}\left(\begin{array}{c}
v \\
2 s
\end{array}\right)\left(h-\frac{1}{2}\right)^{v-2 s} n^{v-2 s} D_{2 n}^{(n)} / 2^{2 s} .
$$

Since $D_{2 n}^{(n)}$ may be written as a polynomial in $n$ of degree $s$, and $D_{0}^{(n)}=1$, it follows readily from (4.4) that, expressed as a polynomial in $n$,

$$
B_{v}^{(n)}(h n)=\left(h-\frac{1}{2}\right)^{v} n^{v}+\text { terms of lower degree. }
$$

Consequently, using the same procedure that gave (3.4), we can show for $a, d$ fixed constants, $i, j=0,1, \cdots, m$, that

$$
\left|B_{i}^{(a+j d)}(h(a+j d))\right|=\prod_{k=0}^{m}\left(h-\frac{1}{2}\right)^{k} d^{k} k ! .
$$

For $h=0,(4.7)$ reduces to the case of Corollary $1(\mathrm{i})$. If $h=1 / 2$ and $v$ is odd, then it follows from (4.4) that 


$$
B_{v}^{(n)}(n / 2)=0
$$

Therefore for $m \geq 1$, the value of the determinant in (4.6) is zero. However, if $v$ is even, then

$$
B_{v}^{(n)}(n / 2)=D_{v}^{(n)} / 2^{2 v}
$$

and

$(4.7)^{\prime}$

$$
\left|B_{2 i}^{(a+j d)}\left(\frac{a+j d}{2}\right)\right|=\left|D_{2 i}^{(a+j d)} / 2^{2 i}\right|=\prod_{k=0}^{m}\left(-\frac{d}{24}\right)^{k}(2 k) !,
$$

where in evaluating the second determinant we have applied Corollary 1 (iii).

Finally, it is of interest to point out that $[1, p .4]$

$$
\Delta^{v} f(x)=\sum_{j=0}^{v}(-1)^{v-j}\left(\begin{array}{l}
v \\
j
\end{array}\right) f(x+j d)
$$

together with $(2.2),(2.4),(2.7),(2.9)$, and (2.10) yield the recursion formulas

$$
\sum_{j=0}^{v}(-1)^{v-j}\left(\begin{array}{l}
v \\
j
\end{array}\right) B_{v}^{(a+j d)}=\left(-\frac{d}{2}\right)^{v} v !
$$

$$
\sum_{j=0}^{v}(-1)^{v-j}\left(\begin{array}{l}
v \\
j
\end{array}\right) C_{v}^{(a+j d)}=(-d)^{v} v !
$$

$$
\sum_{j=0}^{v}(-1)^{v-j}\left(\begin{array}{l}
v \\
j
\end{array}\right) E_{2 v}^{(a+j d)}=\left(-\frac{d}{2}\right)^{v}(2 v) !
$$

and

$$
\sum_{j=0}^{v}(-1)^{v-j}\left(\begin{array}{l}
v \\
j
\end{array}\right) D_{2 v}^{(a+j d)}=\left(-\frac{d}{6}\right)^{v}(2 v) !
$$

5. Some additional results. The above methods may also be applied to the evaluation of determinants involving the classic orthogonal polynomials. We consider first the Laguerre polynomials defined by $[2$, p. 97] 


$$
L_{n}^{(\alpha)}=\prod_{v=0}^{n}\left(\begin{array}{c}
n+\alpha \\
n-v
\end{array}\right) \frac{(-x)^{v}}{v !}
$$

Setting $\alpha=a+j d$ and writing (5.1) as a polynomial in $j$ we have

$$
L_{n}^{(a+j d)}(x)=j^{n} \frac{d^{n}}{n !}+\text { terms of lower degree }
$$

Consequently, as in $§ 3$, we obtain

$$
\left|L_{i}^{(a+j d)}(x)\right|=\prod_{k=0}^{m-1} d^{k}=d^{1 / 2 m(m-1)} \quad(i, j=0,1, \cdots, m-1)
$$

For the Jacobi polynomials defined by $[2, \mathrm{p} .67]$

$$
P_{n}^{(\alpha, \beta)}(x)=\sum_{v=0}^{n}\left(\begin{array}{c}
n+\alpha \\
n-v
\end{array}\right)\left(\begin{array}{c}
n+\beta \\
v
\end{array}\right)\left(\frac{x-1}{2}\right)^{v}\left(\frac{x+1}{2}\right)^{n-v}
$$

we set $\alpha=a+j d$ and hold $\beta$ fixed. Then, as a polynomial in $j$

$$
P_{n}^{(a+j d, \beta)}(x)=j^{n} \frac{d^{n}}{2^{n}} \frac{(x+1)^{n}}{n !}+\text { terms of lower degree } .
$$

Hence, we find

$$
\left|P_{i}^{(a+j d, \beta)}(x)\right|=\left\{\frac{(x+1) d}{2}\right\}^{1 / 2 m(m-1)} \quad(i, j=0,1, \cdots, m-1) .
$$

Similarly

$$
\left|P_{i}^{(a, b+j e)}(x)\right|=\left\{\frac{(x-1) e}{2}\right\}^{1 / 2 m(m-1)} \quad(i, j=0,1, \cdots, m-1) .
$$

We consider next, as a polynomial in $j$,

$$
\begin{aligned}
& P_{n}^{(a+j d, b+j e)}(x) \\
& \quad=j^{n} \sum_{v=0}^{n} \frac{a^{n-v}}{(n-v) !} \frac{e^{v}}{v !}\left(\frac{x-1}{2}\right)^{v}\left(\frac{x+1}{2}\right)^{n-v}+\text { terms of lower degree }
\end{aligned}
$$




$$
=\frac{j^{n}}{n !}\left[\frac{(d+e) x+d-e}{2}\right]^{n}+\text { terms of lower degree, }
$$

which yields

(5.6) $\quad\left|P_{i}^{(a+j d, b+j e)}(x)\right|=\left[\frac{(d+e) x+d-e}{2}\right]^{1 / 2 m(m-1)}$

$$
(i, j=0,1, \cdots, m-1) \text {. }
$$

Finally, for $\alpha=\beta$, the Jacobi polynomials reduce to the ultraspherical polynomials $P^{(\alpha)}(x)$. It follows from $(5.6)$ that

(5.7) $\quad\left|P_{i}^{(a+j d)}(x)\right|=(d x)^{1 / 2 m(m-1)}$

$$
(i, j=0,1, \cdots, m-1)
$$

\section{REFERENCES}

1. N. E. Nörlund, Differenzenrechnung, Berlin, 1924.

2. Gabor Szegö, Orthogonal polynomials, New York, 1939.

DUKE UNIVERSITY 


\section{PACIFIC JOURNAL OF MATHEMATICS}

\section{EDITORS}

\author{
H. L. ROYDEN \\ Stanford University \\ Stanford, California \\ E. Hewitt \\ University of Washington \\ Seattle 5 , Washington
}

R. P. Dilworth

California Institute of Technology Pasadena 4, California

A. HorN*

University of California

Los Angeles 24, California

\section{ASSOCIATE EDITORS}

\author{
H. BUSEMANN \\ HERBERT FEDERER \\ MARSHALL HALL
}

\author{
P. R. HALMOS \\ HEINZ HOPF
}

ALFRED HORN
R. D. JAMES

BORGE JESSEN

PAUL LÉVY
GEORGE PÓLYA

J. J. STOKER

KOSAKU YOSIDA

\section{SPONSORS}

UNIVERSITY OF BRITISH COLUMBIA

CALIFORNIA INSTITUTE OF TECHNOLOGY

UNIVERSITY OF CALIFORNIA, BERKELEY

UNIVERSITY OF CALIFORNIA, DAVIS

UNIVERSITY OF CALIFORNIA, LOS ANGELES

UNIVERSITY OF CALIFORNIA, SANTA BARBARA

MONTANA STATE UNIVERSITY

UNIVERSITY OF NEVADA

OREGON STATE COLLEGE

UNIVERSITY OF OREGON

UNIVERSITY OF SOUTHERN CALIFORNIA

\author{
STANFORD RESEARCH INSTITUTE \\ STANFORD UNIVERSITY \\ UNIVERSITY OF UTAH \\ WASHINGTON STATE COLLEGE \\ UNIVERSITY OF WASHINGTON
}

AMERICAN MATHEMATICAL SOCIETY HUGHES AIRCRAFT COMPANY SHELL DEVELOPMENT COMPANY

Mathematical papers intended for publication in the Pacific Journal of Mathematics should be typewritten (double spaced), and the author should keep a complete copy. Manuscripts may be sent to any of the editors. Manuscripts intended for the outgoing editors should be sent to their successors. All other communications to the editors should be addressed to the managing editor, Alfred Horn at the University of California, Los Angeles 24, California.

50 reprints of each article are furnished free of charge; additional copies may be obtained at cost in multiples of 50 .

The Pacific Journal of Mathematics is published quarterly, in March, June, September, and December. The price per volume (4 numbers) is $\$ 12.00$; single issues, $\$ 3.50$. Back numbers are available. Special price to individual faculty members of supporting institutions and to individual members of the American Mathematical Society: $\$ 4.00$ per volume; single issues, $\$ 1.25$.

Subscriptions, orders for back numbers, and changes of address should be sent to Pacific Journal of Mathematics, c/o University of California Press, Berkeley 4, California.

Printed at Kokusai Bunken Insatsusha (International Academic Printing Co., Ltd.), No. 10, 1-chome, Fujimi-cho, Chiyoda-ku, Tokyo, Japan.

* During the absence of E. G. Straus.

PUBLISHED BY PACIFIC JOURNAL OF MATHEMATICS, A NON-PROFIT CORPORATION COPYRIGHT 1955 BY PACIFIC JOURNAL OF MATHEMATICS 


\section{Pacific Journal of Mathematics}

\section{Vol. 5, No. $2 \quad$ October, 1955}

Leonard M. Blumenthal, An extension of a theorem of Jordan and von

Neumann ........................................ 161

L. Carlitz, Note on the multiplication formulas for the Jacobi elliptic functions.......................................... 169

L. Carlitz, The number of solutions of certain types of equations in a finite

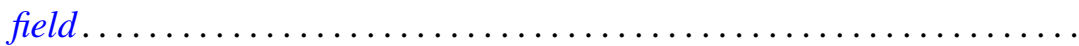

George Bernard Dantzig, Alexander Orden and Philip Wolfe, The generalized simplex method for minimizing a linear form under linear

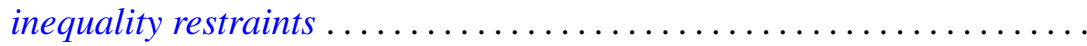

Arthur Pentland Dempster and Seymour Schuster, Constructions for poles and polars in n-dimensions . . . . . . . . . . . . . . . . . . . . 197

Franklin Haimo, Power-type endomorphisms of some class 2 groups ...... 201

Lloyd Kenneth Jackson, On generalized subharmonic functions ......... 215

Samuel Karlin, On the renewal equation ...................... 229

Frank R. Olson, Some determinants involving Bernoulli and Euler numbers of higher order................................ 259

R. S. Phillips, The adjoint semi-group ........................ 269

Alfred Tarski, A lattice-theoretical fixpoint theorem and its applications ... 285

Anne C. Davis, A characterization of complete lattices .............. 311 